\title{
A estrutura heurística da pesquisa sobre religião e processos migratórios - síntese e exemplificação
}

\author{
Frank Usarski*
}

\section{Resumo}

O salto quantitativo de pesquisas sobre a religião e a migração nos últimos anos representa, para a Ciência da Religião, um segundo desafio acadêmico. Além do levantamento constante de dados relativos ao campo em questão e sua análise, há a necessidade de contextualizar as pesquisas singulares em um quadro referencial que reflita a sistemática heurística desse campo na sua totalidade. Este artigo apresenta esse quadro referencial em forma de um modelo composto por três eixos analíticos constitutivos do estudo sobre a relação entre a religião e a migração. A parte final traz alguns exemplos em prol da demonstração da utilidade do esquema.

Palavras-chave: Religião. Migração. Modelo integrativo. Ciência da Religião.

\section{Abstract}

The quantitative leap of research on religion and migration in the last years represents for the Science of Religion a second academic challenge. Besides the continuing collection of empirical data of the field in question and its analysis, there is the demand of contextualizing the singular researches within frame of reference, which reflects the heuristic systematic of the field in its totality. This article introduces such a frame of reference in form of a model composed of three analytical axes constitutive for the study of the relation between religion and migration. The final part offers some examples that demonstrate the utility of the scheme.

Key-words: Religion. Migration. Integrative model. Science of Religion.

\footnotetext{
* Doutor em filosofia pela Universidade de Hanôver, Alemanha. Livre-docente em Ciência da Religião pela PUC-SP. Professor e Coordenador do Programa de Estudos Pós-Graduados em Ciência da Religião da PUC-SP. E-mail: usarski@pucsp.br
} 


\section{Estructura heurística de las investigaciones sobre religión y síntesis de procesos migratorios - síntesis y ejemplificación}

\section{Resumen}

El salto cualitativo de las investigaciones sobre religión y emigración en los últimos años representa, para la Ciencia de la Religión, un segundo desafío académico. Más allá del constante levantamiento de datos relativos al campo en cuestión y su análisis, se hace necesario contextualizar las investigaciones individuales sobre un campo de referencia que refleje la sistemática heurística de este campo en su totalidad. Este artículo presenta dicho cuadro referencial en la forma de un modelo, compuesto por tres ejes analíticos que constituyen el estudio sobre la relación entre religión y emigración. La parte final ofrece algunos ejemplos que demuestran la utilidad del esquema.

Palabras clave: Religión. Emigración. Modelo integrativo. Ciencia de la Religión.

\section{Introdução}

A importância do êxodo para o judaísmo, a suposta invasão dos autointitulados arianos na Índia como impacto decisivo sobre a evolução do hinduísmo e o deslocamento de huguenotes da França para a Prússia são apenas três casos históricos entre inúmeros que apontam para o papel constitutivo de processos migratórios para o surgimento e desenvolvimento das religiões, bem como, para a obrigatoriedade da inclusão deste tópico na pauta acadêmica de cientistas da religião. Sensibilizados para a importância de assuntos relacionados, cientistas da religião integram em suas bibliografias estudos clássicos como o de Emílio Willems acerca da assimilação de imigrantes germânicos e seus descendentes no Brasil (WILLEMS, 1940), ou a obra de Takashi Maeyama a respeito do imigrante japonês e a religião (MAEYAMA).

Ancorados em referências desse tipo e equipados com um bom know how empírico e teórico sobre a relação entre religião e migração, notamos nos últimos anos sinais claros de um engajamento mais acentuado de integrantes da nossa disciplina nas discussões afins. Podemos concluir isso a partir do crescente número de publicações, eventos e grupos de pesquisa relacionados (BRAMADAT \& BILES, 2005). Espera-se esse interesse intensificado de uma disciplina que se autodefine como área empírica, cujos resultados repercutam nas sociedades contemporâneas de acordo com as pretensões da chamada Ciência da Religião aplicada. Comprometidos com o acompanhamento contínuo das dinâmicas dos campos religiosos e preocupados com sua relevância político-social, cientistas da religião sentem-se intelectualmente estimulados pela 
impressionante quantidade de imigrantes no nível internacional, ${ }^{1}$ bem como, pelos múltiplos problemas gerados pelo deslocamento geográfico em massa do ponto de vista tanto dos migrantes quanto das sociedades que os recebem.

O salto quantitativo das articulações acadêmicas acerca de temas afins representa, além de pesquisas próprias sobre a dinâmica migratória em relação à religião, um segundo desafio acadêmico. Diante da diversidade dos projetos já realizados e seu amplo espectro, somos confrontados, além da tarefa constante de levantar e analisar dados específicos relativos ao campo em questão, com a necessidade de contextualizar as pesquisas singulares em um quadro referencial que reflita a sistemática heurística desse campo na sua totalidade. O que está na pauta são perguntas como: como superar um imediatismo dos pesquisadores envolvidos na investigação de determinadas facetas da problemática? Como relacionar, de maneira lógica, as contribuições fornecidas por pesquisadores singulares engajados na investigação do campo? Quais são os campos de intersecção entre o tema "migração e religião" no sentido mais estrito e assuntos "paralelos" ou "complementares", que já fazem parte da nossa agenda acadêmica há um bom tempo, por exemplo, os da "globalização", da diáspora ou da transplantação religiosa?

A tentativa de responder a essas perguntas no decorrer deste texto dá continuidade a uma reflexão em andamento iniciada por uma publicação anterior e que necessita de complementos em vários sentidos. Antes de avançar nesse sentido, o item seguinte traz algumas reflexões metateóricas em prol da justificativa e preparação do raciocínio no corpo principal do texto.

\section{Proposições}

De modo diferente do senso comum, qualquer ciência se caracteriza por um "corpo racionalmente sistematizado [...] de conhecimentos" (FAPESP, 2014, p. 15). Isso significa que o conhecimento produzido por integrantes de uma ciência representa "um saber ordenado logicamente" que supera o risco que os insights resultantes de esforços individuais permaneçam num estágio de "conhecimentos dispersos e desconexos" (MARCONI \& LAKATOS, 2003, p. 80).

Para que um saber coletivamente acumulado transcenda o conhecimento dos membros singulares de uma disciplina, é necessário encaixar a contri-

1 Em 2015, o número estimado era de 244 milhões, cf. http://www.un.org/sustainabledevelopment/blog/2016/01/244-million-international-migrants-living-abroad-worldwidenew-un-statistics-reveal/ <Acesso 12/06/2017> 
buição de cada um em um quadro referencial sistematizado. Trata-se de uma contextualização em um estoque coletivo de conhecimento preestabelecido pela comunidade científica em questão. Esse estoque não apenas representa o que já foi feito pelos integrantes de uma disciplina, mas também aponta para o que deve ser feito a curto e médio prazo em prol do aperfeiçoamento do saber coletivamente construído. Essa funcionalidade da sistematização do conhecimento disciplinar é salientada por Vetter, que identifica problemas científicos propriamente ditos em relação ao reconhecimento de uma lacuna no depósito de conhecimento e a necessidade coletiva de compensar essa falta (VETTER 1975).

O que vale para a ciência em geral ganha uma importância específica no âmbito da Ciência da Religião, que reivindica integridade disciplinar por sua capacidade integrativa de qualquer contribuição acadêmica relevante para o estudo do seu objeto, independentemente do lugar disciplinar original em que tais insights são obtidos. Como em outros casos, essa integração no estoque do conhecimento administrado pela Ciência da Religião acontece de maneira sistemática, o que dá conta de uma das tarefas cruciais da nossa disciplina salientadas por Joachim Wach, na sua tese de livre docência, em 1924. Nessa obra, Wach chamou a atenção para uma tarefa que complementa a abordagem histórica das religiões, isto é, a sistematização dos resultados e insights oriundos de contribuições singulares. É esse ramo do nosso trabalho ao qual Hubert Seiwert se refere quando diz:

O termo 'estudo sistemático das religiões' designa [...] o ramo de pesquisa cujo interesse de conhecimento é direcionado [...] ao arranjo e ordenamento de um campo de objetos. O fato histórico particular transforma-se em uma “ocorrência de algo mais geral" (SEIWERT, 1977, p. 2).

A argumentação de Seiwert é apoiada por Michael Pye, que afirma:

O que é uma disciplina no sentido científico? É, nada mais, do que uma abordagem sistematicamente ordenada para o estudo de um campo. O campo $[\mathrm{da} / \mathrm{s}]$ religião (ões), não menos do que qualquer outro campo, requer uma abordagem sistematicamente ordenada para seu estudo (PYE, 2013, p. 162).

São essas observações metateóricas que justificam e norteiam a busca para a lógica substancial implícita no vasto material sobre a relação entre religião e migração já produzido. 
O seguinte passo do raciocínio desta apresentação reside na identificação, explanação e exemplificação dessa estrutura heurística. Deve se propor que qualquer insight empírico acerca do papel da religião na dinâmica migratória pode ser associado a pelo menos um de três eixos, e que a projeção dessa estrutura tripla na produção acadêmica afim permite um olhar holístico sobre o statu quo da pesquisa no sentido de conquistas e demandas.

\section{A estrutura heurística da pesquisa sobre a relação entre re- ligião e migração}

Partindo da definição de migração como movimento mediante o qual indivíduos deslocam seu centro de vida por um tempo prolongado (TREIBEL, 2008, p. 295) e fazendo uso do conceito de migrante internacional no sentido de uma "pessoa que vive temporária ou permanentemente em um país diferente daquele em que nasceu e com a qual tem adquirido laços sociais significantes", ${ }^{2}$ sugere-se que os insights singulares sobre a relação entre religião e migração podem ser classificados conforme: a) o foco empírico em determinados momentos constitutivos do processo de migração; b) a luz analítica em que a religião aparece em relação à migração; e c) a questão do nível em que a religião se manifesta na dinâmica migratória.

O primeiro eixo representa a cronologia do processo de migração que, na sua totalidade, pode ser subdividido em fases subsequentes aqui simplesmente chamados "antes", "durante" e "depois" do processo do deslocamento do lugar de origem para o lugar de destino. A duração de cada fase é flexível e depende de uma série de fatores adicionais amplamente contemplados na literatura secundária. Reduzindo a complexidade dessa dimensão histórica da migração, recomenda-se uma subdivisão simplificada composta por três momentos principais, isso é, antes, durante e depois da migração, no sentido do deslocamento do país de origem para o país de destino. O maior número de trabalhos sobre a dinâmica migratória refere-se ao "antes" e ao "depois", inclusive as consequências de longo prazo do deslocamento do país de origem. Em comparação, ainda está subdesenvolvido o estado de questão referente aos pré-requisitos para a decisão de migrar e - em parte devido ao difícil acesso empírico a esta fase - à jornada na direção ao país de destino.

A primeira fase é a da situação anterior à migração no sentido de deslocamento do lugar de origem em direção ao destino. Uma das perguntas

2 UNESCO: Migrant/Migration, http://www.unesco.org/new/en/social-and-human-sciences/ themes/ international-migration/glossary/migrant/ <Acesso 31/08/2017>. 
marcantes para a literatura secundária refere-se aos motivos que incentivam o processo de migração. O aspecto crucial, aqui, é a pergunta sobre se a decisão de um indivíduo ou de um conjunto de indivíduos de sair da sua terra é voluntária ou forçada.

A jornada propriamente dita representa a segunda fase. Essa jornada pode ser direta ou segmentada no sentido de estadias intermediárias a caminho do objetivo final. A terceira fase começa com a chegada do migrante à sociedade anfitriã. Vale lembrar da possibilidade de que um lugar considerado apenas transitório (no sentido da caracterização da segunda fase) torna-se o lar duradouro sem que a jornada seja completada conforme inicialmente planejado. Nesse caso, não há ruptura geográfica entre a segunda e a terceira fases.

Alguns autores ampliaram o espectro cronológico do processo do deslocamento e chamaram atenção para os pré-requisitos responsáveis pelo início da dinâmica migratória propriamente dita. De acordo com algumas pesquisas, apesar de existirem fortes razões para uma migração, há indivíduos que decidem permanecer no seu lugar de origem. Observações desse tipo trouxeram à tona a pergunta sobre as razões subjacentes na desistência ou nas medidas concretas em prol de migração. Algo análogo pode-se dizer da chegada ao destino. Nem todas as pessoas que entram num país estabelecem-se nele para sempre. Em relação àqueles que ficam por um bom tempo ou permanentemente, sabe-se que as decisões tomadas por eles na sociedade anfitriã têm consequências profundas, não apenas para as próprias existências e as dos seus filhos, mas também para a comunidade deixada para trás e para o novo ambiente em que se inserem.

A dimensão das consequências é constituída pela relação de médio e longo prazo entre o imigrante e seu novo ambiente. Ambos os polos dessa dinâmica são de nosso interesse. A depender da frequência, duração e o número de indivíduos envolvidos, a migração tem não apenas um impacto na vida dos imigrantes, mas também sobre a vida da sociedade anfitriã.

Quanto aos imigrantes, aspectos como os seguintes devem ser levados em consideração: o migrante é adulto ou adolescente? Ele imigrou legalmente? Ele veio sozinho ou com outros membros da sua família? Ele é praticante de uma religião? Seu cotidiano é marcado pelos costumes e normas dessa religião? A vivência da sua religião depende do suporte de uma comunidade? Sua situação psicológica o torna apto ao conforto emocional e à superação da contingência promovidos por uma comunidade religiosa? (CONNOR, 2013, s.p.). Qual é o nível da sua formação e sua competência linguística? 
(POWERS, 2013, s.p.). Ele está preparado e disposto para buscar laços com pessoas além da comunidade étnica composta por migrantes da mesma origem nacional? (TSANG, 2015). Simultaneamente, são relevantes questões referentes às circunstâncias nacionais encontradas no país do destino pelos imigrantes. No país de destino, como a migração é juridicamente regulamentada? A migração é desejada ou, até, essencial para a evolução econômica do país? O governo definiu limites numéricos anuais de migrantes? (TREIBEL 2008, p. 295). O país ratificou a convenção internacional referente à eliminação de todas as formas de discriminação racial (Elimination of All Forms of Racial Discrimination) (BANTON, 2013, s.p.). Algumas áreas profissionais em que determinados migrantes atuam desfrutam de privilégios? Há uma religião dominante no país de recepção? Ela se engaja na recepção de migrantes? Como ela reage a supostos concorrentes no mercado religioso?

O seguinte gráfico aponta para os componentes do processo migratório esboçados.

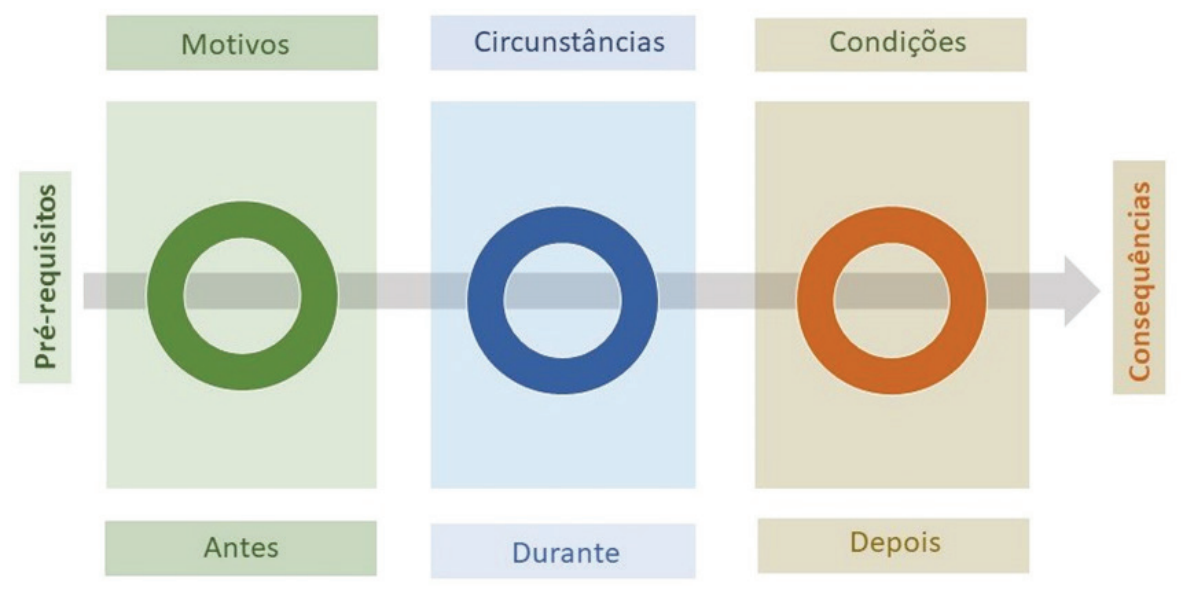

O segundo eixo estrutural da investigação do nosso objeto tem a ver com a questão: a religião, como um dos componentes da relação entre religião e migração, é tratada como variável dependente ou independente? Isso significa para um cientista da religião engajado na pesquisa acerca da relação entre religião e migração que ele pode focar ou fatores religiosos que impulsionam a migração ou o impacto de processos de migração sobre a religião. 


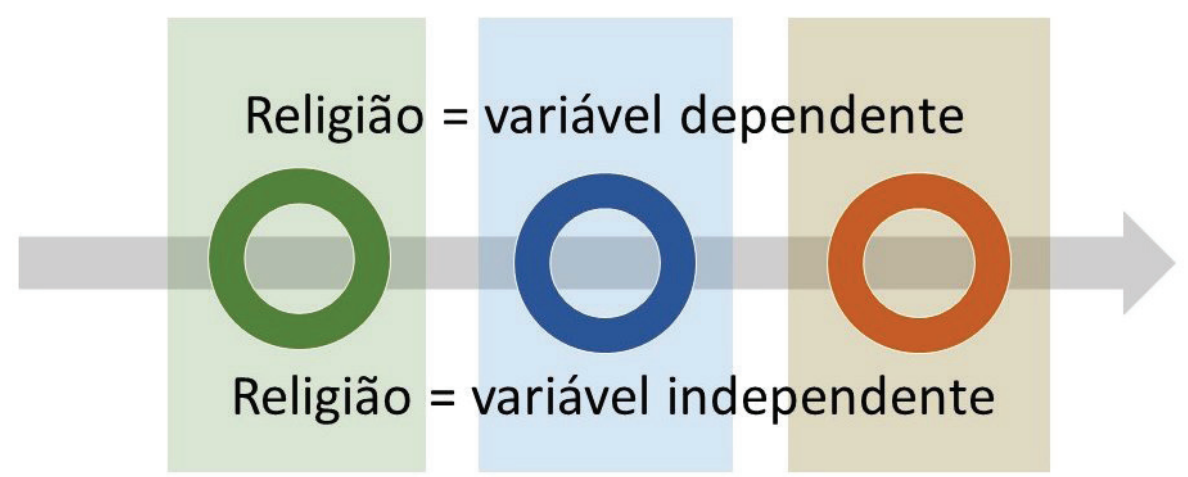

Em ambos os casos, um projeto tem que esclarecer a que categoria da religião a pesquisa se refere. Trata-se de uma religião étnica preocupada com a preservação de práticas moldadas em uma cultura específica e enraizadas em uma estrutura comunitária diferenciada? Se sim, quais são as estratégias de manutenção de costumes e os modos de interação na nova sociedade anfitriã e como eventuais adaptações ao novo ambiente - no sentido de inovações religiosas - são recebidas pelas autoridades no país de origem? Caso o objeto seja uma religião universal interessada na expansão global, seria interessante saber se as ambições proselitistas são vistas por outras religiões universais presentes ou, até mesmo, predominantes na sociedade anfitriã? Qual é o potencial ecumênico da religião migrada? A religião recém-chegada é uma religião antiga, já predefinida por uma longa história de existência marcada por um corpo consolidado e normativo de dogmas e práticas, ou ela cabe na categoria de uma "nova religião" ainda moldável, cujo contato com uma nova cultura é considerado uma chance para a ampliação do seu repertório religioso?

O exemplo clássico de migração voluntária impulsionada por motivos religiosos é a missão, desde que os agentes dessa missão "adquiram laços sociais significantes" com a sociedade em que buscam prosélitos. A perseguição sistemática de sujeitos por causa da sua religião e a decisão dos perseguidos de fugir das restrições e do mau tratamento do seu habitat em busca de condições que permitam a vivência da própria fé em liberdade representam uma migração involuntária, sobretudo impulsionada por motivos religiosos. Outro tipo de migração é tipicamente vinculado à esperança de que a mudança de país ofereça oportunidades econômicas extraordinárias ou a eventos prejudiciais de força maior, como guerras ou catástrofes ambientais. Nesses casos, são primariamente aspectos não religiosos que impulsionam a 
Integrando os primeiros dois eixos estruturantes, alguns exemplos simples se impõem.

\section{Religião}

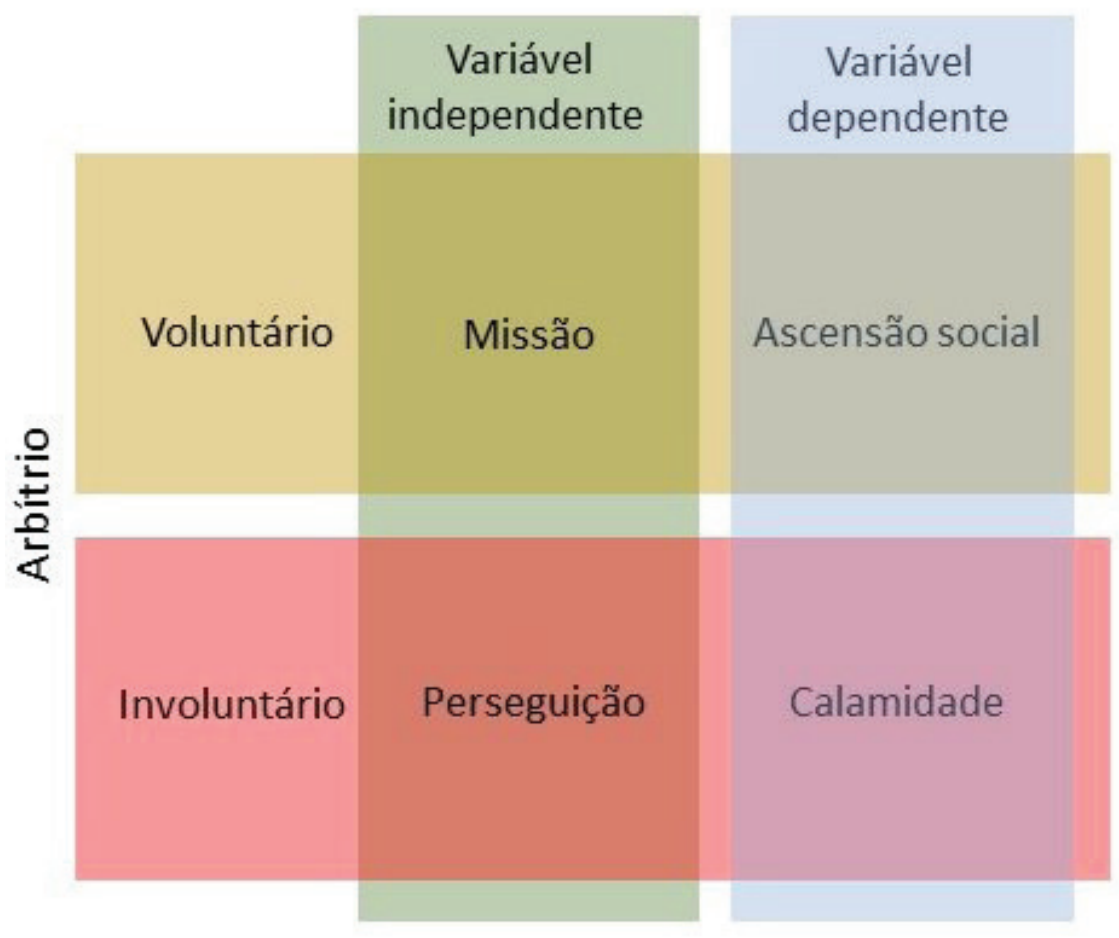

migração, o que não significa que a dimensão religiosa seja completamente irrelevante para o processo migratório, seja como fator do fundo ou como um elemento que se faz sentir mais fortemente em uma fase posterior $\mathrm{da}$ saída do país de origem.

Em complementação aos primeiros dois eixos analíticos, há um terceiro elemento que determina os estudos das relações entre migração e religião, a saber: o nível em que os fenômenos religiosos considerados relevantes para pesquisas afins são concebidos. Além do nível individual - ou micro - que até agora norteou grande parte do raciocínio deste artigo -, há dois outros que correspondem às seguintes perguntas: a dinâmica migratória envolve uma tradição religiosa na íntegra (nível macro) no sentido de um fenômeno filosófico, cultural, social? Interessam a determinadas instituições (nível meso) que representam determinada tradição religiosa? 


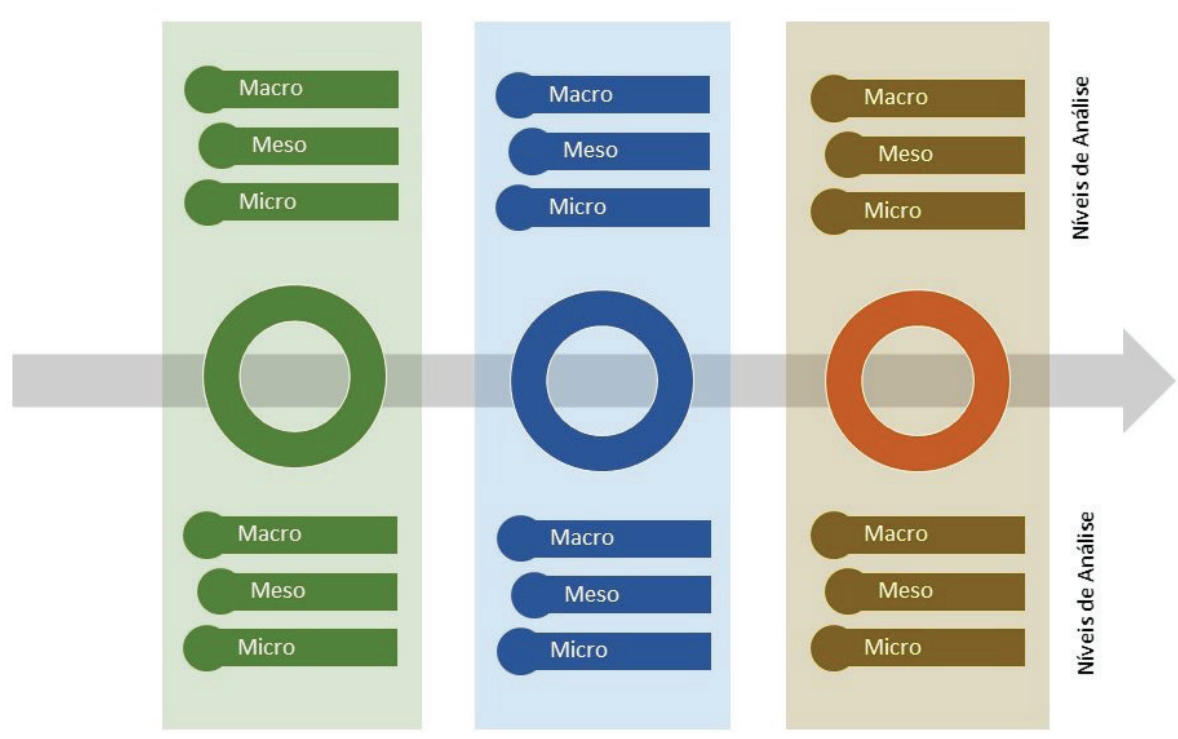

A migração de uma religião na íntegra é um evento histórico não muito frequente. Um exemplo é o deslocamento ("hégira") da comunidade primitiva de muçulmanos para Medina. Pressionados pela população maioritária de Meca, Mohamed e seus seguidores sofreram tensões cada vez mais intensas com a maioria dos habitantes, o que fez que, em setembro de 622 d.C., os integrantes da nova religião se mudassem para Medina. Privados da proteção tribal, cada convertido se viu diante de um vácuo normativo gradativamente preenchido por novas revelações recebidas por Mohamed na cidade de exílio. A comparação entre as suras de Meca (610-622) e as suras de Medina (622632) revela o salto evolutivo do Islã em consequência à hégira e não é por acaso que a migração para Medina deu início ao calendário islâmico.

Geralmente, o envolvimento de religiões em processos migratórios ocorre por meio de determinadas instituições ou por suas representantes oficiais. Há inúmeros exemplos da relevância analítica desse nível meso, entre eles o caso do pioneiro do budismo institucional no Brasil, o reverendo Tomojiro Ibaragi, que fez parte da primeira leva de imigrantes japoneses que chegaram em 18 de junho de 1908 ao porto de Santos. O sacerdote, que representava sua ordem Honmon Butsuryū-shū, prestou serviço religioso para os seus contemporâneos recém-chegados ao país e fundou, em 1936, na cidade paulista de Guaiçara, o templo Taissenji, a primeira instituição budista em solo brasileiro (USARSKI, 2016, p. 720). 
Integrando os três eixos analíticos em um único plano, chega-se ao seguinte resultado:

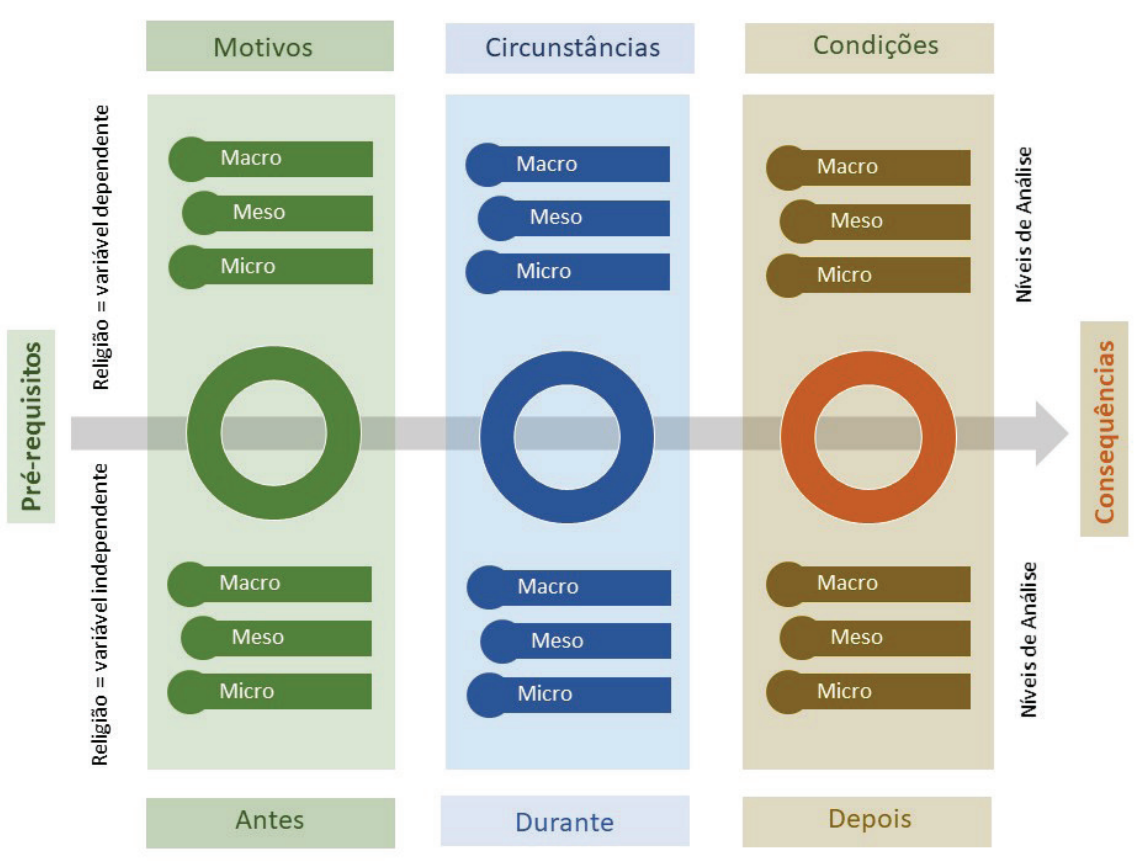

\section{Exemplificações}

O quadro acima pretende representar a estrutura lógica do campo de estudo sobre a relação no sentido dos problemas até agora abordados por projetos singulares afins. O modelo serve? Aqui, não há espaço para a elaboração de um espectro exaustivo de exemplos em prol da comprovação da pertinência do esquema citado. Em vez disso, tem-se que contentar com uma pequena amostra da sua utilidade heurística. Em cada caso serão indicadas as dimensões analíticas contempladas pelas pesquisas selecionadas.

\section{Exemplo 1: Item "pré-requisitos" - nível micro - religião como variável independente}

O primeiro exemplo refere-se ao item "pré-requisitos" que, em termos cronológicos, antecedem à primeira fase do processo migratório propriamente dito. Uma das poucas pesquisas sobre essa dimensão é de autoria de Hoffman, Marsiglia e Ayers (2015), que se interessaram pelo papel da chamada "religiosidade interna" como fator estimulante da migração. Em termos da 
diferenciação entre os três níveis de análise, trata-se de um estudo direcionado ao nível "micro". Além disso, o estudo caracteriza-se pelo tratamento da religião como variável independente. Com essas escolhas analíticas, os autores levantaram dados sobre estudantes matriculados em um programa de ensino superior no Estado de Guanajuato, México. As informações indicam que, apesar da autoavaliação como "religiosos" e do desejo comum de se mudar para os EUA por razões profissionais, indivíduos engajados na vida comunitária de igrejas locais são tendencialmente menos dispostos a migrar do que colegas de classe comprometidos com valores e hábitos espirituais, sem sentir a necessidade de criar laços coletivos em prol dos seus ideais. No primeiro caso, caracterizado como "religiosidade externa", as correlações observadas apontam para a importância de relações humanas por meio das quais os sujeitos se inserem em uma rede social homogênea. A estrutura normativa do grupo coeso gera a sensação de segurança e alimenta a consciência de perda de algo existencialmente importante em caso de migração. A "religiosidade interna", por sua vez, reside na sensação de uma conexão com o divino independente de qualquer grupo e lugar; ela é um fator constitutivo da migração, pois esse tipo de religiosidade é "transportável" e seu deslocamento não implica "custos" afetivos ou, até mesmo, um sentimento de culpa por abandonar um círculo ancorado em princípios como confiança e solidariedade.

\section{Exemplo 2: A cronologia do processo de migração - nível micro - religião como variável dependente}

Um exemplo de muitos estudos sobre a cronologia do processo de migração no sentido de "antes", "durante" e "depois" é o trabalho de Hagen e Ebaugh (2003). As autoras, focadas no nível micro de análise e norteadas pela perspectiva da religião como variável dependente, interessaram-se pela migração ilegal de membros de uma comunidade maya no Oeste da Guatemala para Houston, Texas (EUA), por motivos econômicos. A questão principal de Hagen e Ebaugh foi sobre o papel que igrejas pentecostais desempenharam no decorrer dessa dinâmica. Para as autoras, o "antes" da migração abrange a tomada da decisão de sair do país e a preparação para a viagem. A determinação para o deslocamento resulta de um balanço positivo da relação entre custo e benefício da migração e superação das dúvidas sobre os riscos envolvidos. Pastores de igrejas evangélicas locais procurados como interlocutores assumem o papel de conselheiros tanto para o futuro migrante quanto para 
a sua família. As dicas transcendem a esfera espiritual e se referem também a questões logísticas, por exemplo, a escolha do chamado "coyote", isto é, o guia pago que levará o migrante até o país de destino. A participação intensificada na vida religiosa comunitária das pessoas envolvidas faz parte da preparação da viagem e acompanha outras medidas em prol da partida, por exemplo, o fornecimento de documentos de identidade. O "durante" da migração, ou seja, a viagem do lugar de origem em direção ao lugar de destino é caracterizada por uma série de obstáculos intensificados pela duração da jornada e a necessidade de passar de maneira não oficial por duas fronteiras nacionais. Durante todo esse tempo, a família do migrante, acompanhada pelo pastor, espera no país de origem por notícias e dá continuidade às orações e a ida às reuniões da igreja local. Se for necessário, o pastor entrará em contato com a comunidade irmã em Houston, particularmente se o migrante for preso e necessitar de suporte jurídico e espiritual em loco. O contato com o pastor na Guatemala não termina com a chegada a Houston. Ao contrário, muitas vezes ele é o primeiro a receber a informação da jornada bem-sucedida e a divulga para os membros da comunidade doméstica, o que pode estimular a partida de outros integrantes do grupo para Houston. Paralelamente, a igreja irmã em Houston ganha importância, não apenas por reproduzir a cultura maya e suas práticas, mas também por representar uma estrutura institucional e assistência social relativa às necessidades básicas dos recém-chegados como alojamento e trabalho. O estudo de Hagen e Ebaugh atinge a dimensão das consequências de longo e médio prazo da migração quando revela o desenvolvimento de vínculos religiosos transnacionais a partir do momento em que o migrante tiver atingido um nível razoável de adaptação ao seu novo ambiente. Além do apoio financeiro oferecido pelo migrante para membros da sua família e para a sua igreja local na Guatemala, a igreja binacionalmente organizada opera como intermediadora entre as duas comunidades por ocasião de celebrações coletivas de rituais do ciclo biográfico ou nos EUA ou na Guatemala.

\section{Exemplo 3: Fase "depois" - nível macro - religião como va- riável dependente}

Como terceiro exemplo, cita-se, aqui, uma pesquisa de Hoskins (2015) que se refere a uma tradição religiosa no sentido macro analisada como variável dependente das circunstâncias encontradas por um grupo de praticantes depois do seu estabelecimento em um lugar de destino de migração. Con- 
cretamente falando, trata-se de mudança do espiritismo autóctone ${ }^{3}$ mantido por grupos de vietnamitas que saíram do seu ambiente rural em busca de ascensão social em determinadas metrópoles asiáticas. A pesquisadora observou que os integrantes desses círculos não abandonaram suas orientações religiosas, mas transformaram e atualizaram o repertório do espiritismo autóctone originalmente vinculado a terreiros perto dos seus vilarejos. O que facilitou a "comigração" do panteão doméstico é o fato de que o contato com esses seres é feito via manifestação dos mesmos nos corpos de adeptos. No lugar de destino: os espaços sagrados organizados no lugar de destino foram interpretados pelos sujeitos como "sombras" ou "reflexões" dos terreiros originais. As próprias práticas religiosas foram reinterpretadas. Nem todos representaram meramente ecos de práticas tradicionais. Vários rituais foram transformados ou, até mesmo, inventados, de acordo com as novas funções cumpridas pelos espíritos em reação a desafios não conhecidos em ambientes rurais.

\section{Exemplo 4: Fase depois - consequências - nível meso - religião como variável dependente}

O quarto exemplo, ou seja, a teoria de transplantação religiosa de PYE (1969) corresponde à fase "depois" da dimensão cronologia da migração, ao item "consequências" no sentido de efeitos de longo prazo em reação à imigração em um país alheio e ao nível meso. A religião é tratada como variável dependente, no sentido em que é exposta à influência de fatores gerados pela migração. O estudo de Pye chama a atenção para o fato de que a migração de representantes de uma corrente religiosa pode ter um efeito modificador sobre o repertório espiritual da última. A disseminação além das suas fronteiras iniciais confronta os representantes da comunidade com o desafio de se relacionar de maneira bem-sucedida com as condições encontradas nos horizontes culturais para os quais avançam. Trata-se de um processo complexo de comunicação que, do ponto de vista dos portadores da nova oferta religiosa, oscila entre os polos de manutenção da autenticidade e de inovação. Segundo Pye, quando uma instituição religiosa pretende se enraizar em um novo ambiente, os representantes dessa tradição veem-se obrigado a adaptar o repertório doutrinário, prático e organizacional da comunidade às necessidades e às preferências do público potencial. Mais para

3 Esse tipo de espiritismo aproxima-se do conceito do "animismo", portanto, não deve ser confundido com o espiritismo fundado por Allan Kardec. 
a frente, essa abertura pode ser problematizada pela hierarquia religiosa, caso esta tenha a impressão de que as modificações causadas pela acomodação às novas circunstâncias estão pondo em risco o capital cultural que constituiu a identidade da religião antes da sua difusão na sociedade anfitriã. A partir de sentimentos de ambiguidades entre tradição e inovação, pode-se inaugurar uma busca em prol de restauração de elementos que, embora tivessem sido cruciais do ponto de vista da identidade religiosa, acabaram enfraquecidos ou, até mesmo, foram abandonados no decorrer do estabelecimento no novo ambiente. Surgem, então, reflexões sobre a herança religiosa em que são enfatizados aqueles elementos constitutivos e reforçadas as fronteiras entre o "próprio" e o "estranho".

\section{Exemplo 5: Item consequências - nível meso - religião como variável dependente}

O estudo de Prebish (2003) sobre a adaptação de determinada linha do Budismo Theravada institucionalizada em consequência a ondas de imigração do Sul e Sudeste da Ásia para a Suíça e a Califórnia, EUA, representa o quinto exemplo. A pesquisa destaca - de acordo com a teoria de transplantação religiosa - o nível meso e as modificações sofridas por uma religião em consequência ao processo migratório. Os sujeitos de pesquisa de Prebish eram monges associados a mosteiros budistas desafiados pela necessidade de afrouxar algumas normas tradicionais incompatíveis com os costumes e o senso comum da sociedade anfitriã. Com o tempo, foram abandonadas regras como as de que um monge só pode possuir três túnicas, tomar sua última refeição diária antes do meio-dia e não pode usar um veículo para se deslocar.

\section{Exemplo 6: Fase "depois" - nível micro - religião como variável dependente}

O sexto e último exemplo é o da pesquisa de Logan (2014) sobre a situação de habitantes recém-chegados a um bairro de Toronto chamado Parkdale. Trata-se de um estudo sobre o impacto da religião como variável independente na vida de imigrantes, sobretudo, no sentido micro na fase cronológica da dinâmica migratória identificada em nosso esquema analítico pela coluna "depois". A pesquisa demonstra como uma religião, nesse caso o budismo, pode ajudar a superar os desafios causados pelo deslocamento para um país cujos padrões culturais diferem significativamente de cosmovisões e hábitos religiosos tradicionais de imigrantes. Os pesquisadores estavam 
interessados na relação emocional que os integrantes tibetanos estabeleceram com seu novo "lar", conceito êmico usado pelos entrevistados para se referir não apenas ao próprio apartamento, mas também ao prédio e, até mesmo, à rua em que a família se localizava. Os resultados indicam o papel psicológico crucial desempenhado pela religião trazida para o Canadá. Elementos relevantes nesse sentido estavam em um canto no apartamento reservado para as práticas budistas, como uma cerimônia frente a um altar, bandeiras de oração e a veneração da imagem do Dalai Lama. Foram avaliados depoimentos sintomáticos dos entrevistados, como: "Quando estou depressivo, um olhar para meu altar e uma oração me confortam"; "Um altar em casa traz o sentimento de segurança, sei que nada de mal acontece"; "Possuir uma foto do Dalai Lama é tão aconchegante, acalma e pacifica".

\section{Considerações finais}

Pode-se continuar por horas citando pesquisas que ilustrassem a adequação do esquema analítico elaborado ao longo desta apresentação. Em vez disso, o leitor é convidado a testar a utilidade do modelo por conta própria, seja no sentido da localização de pesquisas já realizadas em um quadro analítico geral, seja no sentido de um incentivo a contribuir para a pesquisa aprofundada acerca da relação entre migração e religião. Em todos os casos, qualquer sugestão em prol de correção ou aperfeiçoamento do esquema apresentado será bem-vinda.

\section{Referências}

BANTON, M. Discrimination and migration: national and ethnic origin, Encyclopedia of Global Human Migration, 2013, DOI: 10.1002/9781444351071.wbeghm176.

BRAMADAT, P. A.; BILES, J. The Re-emergence of Religion in International Public Discourse. Journal of International Migration and Integration, v. 6, n. 2, p. 171-176, Spring 2005.

CONNOR, P. Religion and migration: Encyclopedia of Global Human Migration, 2013, DOI: 10.1002/9781444351071.wbeghm438.

FAPESP. Código de Boas Práticas Científicas. São Paulo, SP: Fundação de Amparo à Pesquisa do Estado de São Paulo, 2014.

HAGAN, J.; EBAUGH, H. R. Calling upon the Sacred: Migrants Use of Religion in the Migration Process. International Migration Review, v. 37, n. 4, p. 1.145-1.162, Winter 2003. 
e processos migratórios - sintese e exemplificação

HOFFMAN, S.; MARSIGLIA; F. F.; AYERS, S. L. Religiosity and Migration Aspirations among Mexican Youth. Journal of International Migration \& Integration, v. 16, n. 1, p. 173-186, February 2015.

HOSKINS, J. A. What Is a Refugee Religion? Exile, Exodus, and Emigration in the Vietnamese Diaspora. In: HORSTMANN, A.; JUNG, J.-H. (Orgs.). Building Noah's Ark for Migrants, Refugees, and Religious Communities. New York: Palgrave Macmillan 2015.

LOGAN, J.; MURDIE, R.: Home in Canada? The Settlement Experiences of Tibetans in Parkdale, Toronto. Journal of International Migration and Integration, v. 17, n. 1, p. 95-113, February 2016.

MAEYAMA, T. O imigrante e a religião: estudo do uma seita religiosa japonesa em São Paulo, 1967, 335 p. Dissertação (Mestrado) - USP, São Paulo, SP.

MARCONI, M. de A.; LAKATOS, E. M. Fundamentos de Metodologia Científica. São Paulo: Atlas, 2003.

POWERS, M. G. Assimilation, integration, and incorporation. Encyclopedia of Global Human Migration, 2013, DOI: 10.1002/9781444351071.wbeghm047.

PREBISH, C. S. Varying the Vinaya: Creative Responses to Modernity. In: HEINE, Steven; PREBISH, Charles, S. (orgs.) Buddhism in the modern world: adaptations of an ancient tradition. New York: Oxford University Press 2003, p. 45-73.

PYE, M. Field and Theory in the Study of Religions. In: PYE, M. Strategies in the Study of Religions. Volume One: Exploring Methods and Positions. Berlin \& Boston: DeGruyter, 2013.

PYE, M. The Transplantation of Religions. Numen, v. 16, n. 1, p. 234-239, 1969.

SEIWERT, H. Systematische Religionswissenschaft: Theoriebildung und Empiriebezug, Zeitschrift für Missionswissenschaft und Religionswissenschaft, v. 61, p. 1-18, 1977.

TREIBEL, A. Migration. In: BAUR, N.; KORTE, H.; LÖW, M.; SCHROER, Markus (Orgs.). Handbuch Soziologie. Wiesbaden: Verlag für Sozialwissenschaften, 2008.

TSANG, W. Y. Integration of Immigrants: The Role of Ethnic Churches. Journal of International Migration \& Integration, v. 16, n. 4, p. 1.177-1.193, 2015.

USARSKI, Frank. O Budismo de imigrantes japoneses no âmbito do Budismo brasileiro, Horizonte, v. 14, n. 43, p. 717-739, jul./set. 2016.

VETTER, B. Das Forschungsproblem. In: FRIEDRICH, W.; HENNING, W. [Hrsg.] Der sozial-wissenschaftliche Forschungsprozeß. Zur Methodologie, Methodik und Organisation der marxistisch-leninistischen Sozialforschung. Berlin: Deutscher Verlag der Wissenschaften, 1975.

WILLEMS, E. Assimilação e populações marginais no Brasil; estudo sociológico dos imigrantes germânicos e seus descendentes. São Paulo: Companhia Editora Nacional, 1940.

Submetido em: 21-09-2017

Aceito em: 13-11-2017 